\title{
Effects of the Size and Morphology of Cementite Particles on the Annealing Texture in Low-carbon Aluminium-killed Steel ${ }^{*}$
}

\author{
By Hideo ABE, ${ }^{* *}$ Takeshi SUZUKI** and Kimihiko TAKAGI***
}

\begin{abstract}
Synopsis
The processes of cementite dissolution, recrystallization and annealingtexture formation during isothermal annealing have been observed in coldrolled sheets of a low-carbon aluminium-killed steel in which the effect of the pre-precipitation clusters of aluminium-nitride was eliminated by preliminary heat-treatments. Inhibition of nucleation due to pinning of dislocations by dissolved carbon atoms and inhibition of the growth of recrystallized grains by carbon atoms or by fine cementite particles have been considered as probable effects which decrease the rate of recrystallization. The predictions were, however, found to be inconsistent with the experimental results obtained. It was supposed that different annealing textures were produced through changes in the size and distribution of constrained-deformation regions in the deformed iron matrix. When the cementite particles were coarse and widely spaced, an annealing texture with strong $\{222\}$ and weak $\{110\}$ orientations was obtained by rapid heating directly to a high temperature. In a case when the hot band contained fine spheroidal cementite particles, a similar annealing texture could be obtained by two-stage annealing. The presence of pearlite had a deteriorating effect on the development of the favourable texture.
\end{abstract}

\section{Introduction}

Concentration of carbon in solution has been thought to be one of the factors which control the annealing texture in low-carbon sheet steels. This is information deduced from a large number of engineering studies on the annealing texture as a function of metallurgical and process variables. ${ }^{1-4)}$ An early study $^{1)}$ showed that processing from a hot band of low-carbon steel, supersaturated with respect to carbon, resulted in formation of a recrystallization texture with an increased amount of $\{\mathrm{hk} 0\}\langle 001\rangle$ components. Since then, the effect of carbon in solution on the annealing texture has been one of the foci of attention for research workers in the field of sheet steel industry. ${ }^{3,4)}$

In a study of annealing textures in low-carbon sheet steels processed through a simulated continuous annealing line, Kubotera et al. ${ }^{2)}$ showed that processing from a hot band, in which cementite particles had been coarsened, resulted in an annealing texture with the strong $\{222\}$ sheet-plane orientations favourable for deep-drawing applications. They proposed that the rate of dissolution of cementite particles into the iron matrix would be decreased with increasing the size of the cementite particles and that the recrystallization proceeded in the deformed iron matrix containing less amount of carbon in solution led to the development of the favourable annealing texture. However, there raised an objection that the size and spacing of cementite particles contained in the hot band would have an influence on the deformed struc- ture by which the annealing texture must have been controlled. Moreover, because of a lack of quantitative data on the rate of cementite dissolution, it was uncertain whether the most adequate heat-cycle could be settled on the basis of their argument.

The present study has been undertaken to present quantitative data on the dissolution of cementite particles, which are to be correlated with the processes of recrystallization and annealing-texture formation.

\section{Experimental}

The starting material was a hot band, $2.96 \mathrm{~mm}$ thick, of a low-carbon aluminium-killed steel. The chemical composition is given in Table 1. Three specimens prepared from the hot band, designated as $\mathrm{A}, \mathrm{B}$, and $\mathrm{C}$, were subjected to heat-treatments as illustrated schematically in Fig. 1. An argon-flow tube furnace was used for heating to $920^{\circ} \mathrm{C}$ and $710^{\circ} \mathrm{C}$. The microstructures of these specimens after the heat-treatments are shown in Photo. 1. Specimen A contains fine spheroidal cementite particles, specimen B pearlite aggregates or eutectoid cementite particles located along grain boundaries, and specimen $\mathrm{C}$ very large cementite particles with concave

Table 1. Chemical composition (wt \%).

\begin{tabular}{cccccccc}
\hline G & Si & Mn & P & S & sol. Al & $\begin{array}{c}\text { insol. } \\
\mathrm{Al}\end{array}$ & sol. N \\
\hline 0.046 & 0.01 & 0.35 & 0.020 & 0.018 & 0.030 & 0.010 & 0.0060 \\
\hline
\end{tabular}

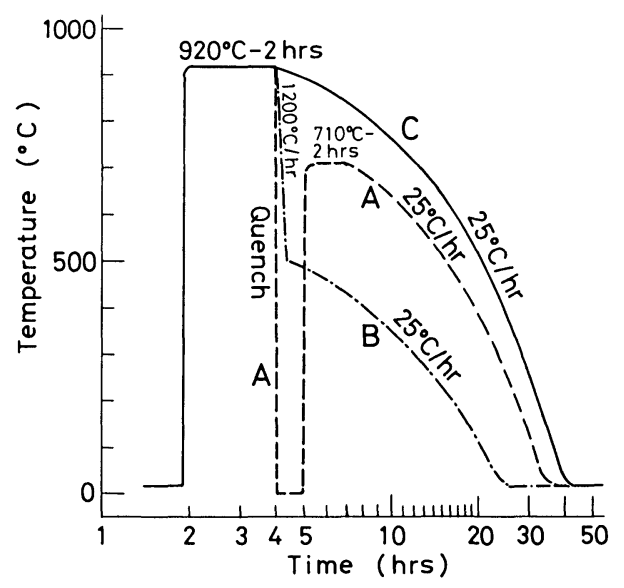

Fig. 1. Schematic diagram showing heat-treatments given to specimens A, B, and C prior to cold rolling.

\footnotetext{
* $\quad$ Presented at the 98th ISIJ Meeting October, 1979, at Nagoya University, Nagoya. Manuscript received December 18 , 1979.

** Department of Metallurgy and Materials Science, The University of Tokyo, Hongo, Bunkyo-ku, Tokyo 113.

*** The Graduate School, The University of Tokyo.
} 


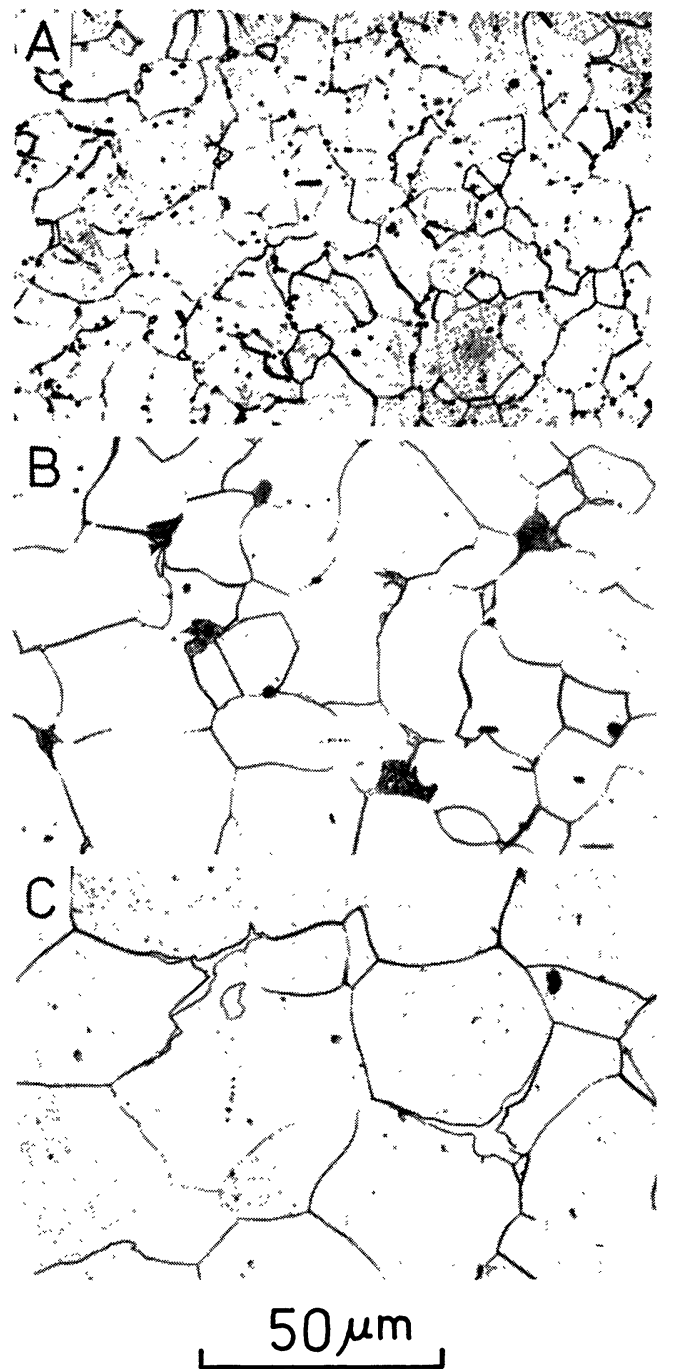

Photo. 1. Optical microstructures of specimens A, B, and C after respective heat-treatments shown in Fig. 1.

interfaces along the edges or corners of ferrite grains.

Immediately after the respective heat-treatments, these specimens were cold rolled at room temperature to a reduction of $75 \%$ in thickness. A large number of test-pieces, $100 \mathrm{~mm}$ by $4 \mathrm{~mm}$ by $0.74 \mathrm{~mm}$, were prepared from the cold-rolled sheets. These testpieces were isothermally annealed for various times in a salt bath kept at $695^{\circ} \mathrm{C}, 650^{\circ} \mathrm{C}, 600^{\circ} \mathrm{C}$ or $550^{\circ} \mathrm{C}$, and quenched into iced water. Then, electricalresistivity measurements were made at liquid-nitrogen temperature. Besides, hardness measurements were made on the reference test-pieces.

In order to determine the amount of carbon atoms occupying the normal interstitial sites of dislocationfree regions in the iron matrix, every test-piece was additionally tempered at $250^{\circ} \mathrm{C}$ for $50 \mathrm{hr}$ and the accompanied change in resistivity was observed. It was assumed ${ }^{5)}$ that the carbon atoms occupying the normal interstitial sites would almost completely precipitate as cementite during the $50 \mathrm{hr}$-tempering at $250^{\circ} \mathrm{C}$, whilst those trapped by dislocations would not be released by the tempering. Hence, the observed decrement in resistivity by the tempering at $250^{\circ} \mathrm{C}$, divided by $29.5 \mu \Omega \cdot \mathrm{cm} / \mathrm{wt}^{\circ} \%,{ }^{6)}$ would give the amount of carbon atoms that had occupied the normal interstitital sites. In the present paper, the amount of carbon thus obtained is called " nominal dissolved carbon content."

It should be noticed that the nominal dissolved carbon content thus obtained is not exactly that dissolved at the isothermal annealing temperature but smaller by the amount segregated to dislocations during the quenching operation. ${ }^{5)}$ It is well known that the ratio of the number of carbon atoms trapped by dislocations, $n_{d}$, to that occupying the normal interstitial sites, $n_{l}$, is given by

$$
n_{d} / n_{l}=\left[\left(\mathcal{N}_{d}-n_{d}\right) /\left(\mathcal{N}_{l}-n_{l}\right)\right] \cdot \exp [E / k T]
$$

where $\mathcal{N}_{d}\left(=4.0 \times 10^{7} \cdot \rho_{d} \mathrm{~cm}^{-3}\right)$ is the number of probable dislocation sites, $\mathcal{N}_{l}\left(=2.5 \times 10^{23} \mathrm{~cm}^{-3}\right)$ the number of normal interstitial sites, $E$ the interaction energy of the order of $0.5 \mathrm{eV},{ }^{7,8)}$ and $k$ the Boltzmann constant; $\rho_{d}$ is the dislocation density. According to Eq. (1), the amount of carbon atoms trapped by dislocations is a function of three variables; $n_{l}, \rho_{d}$ and temperature $T$. Within the ranges of $n_{l}$ and $T$ covered in the present study, $n_{d}$ is negligibly small when $\rho_{d}$ is lower than $10^{9} \mathrm{~cm} / \mathrm{cm}^{3}$. However, for higher dislocation densities, the nominal carbon content observed should be corrected by adding the amount of carbon segregated to dislocations. Evaluation of $n_{d}$ may be possible either by the observation of the "cold-work peak" in the internal friction spectrum $^{7)}$ or by thermoelectric-power measurements. ${ }^{5)}$ This work is left for future studies. In the present paper, merely a qualitative consideration has been made on the amounts of carbon atoms trapped by dislocations during the quenching operation.

After tempering at $250^{\circ} \mathrm{C}$, pole density, fraction recrystallized, and hardness were measured after removing a quarter of the specimen thickness from one side only by mechanical and chemical polishing. The pole-density measurements were made with (110), (200) and (222) X-ray diffraction lines by monochromatized $\mathrm{Mo}-\mathrm{K} \alpha$ radiation. The fraction recrystallized was determined by the point-counting method on an optical micrograph with a magnification of 600 times.

\section{Results}

The data of electrical resistivity for the determination of nominal dissolved carbon content are illustrated in Fig. 2 for the case of isothermal annealing at $600^{\circ} \mathrm{C}$. Open marks of circle, triangle and square in Fig. 2 (a) are respectively the data-points for specimens $\mathrm{A}, \mathrm{B}$ and $\mathrm{C}$, having cold rolled to a reduction of $75 \%$, isothermally annealed for various times at $600^{\circ} \mathrm{C}$ and quenched into iced water. Filled marks in the same figure are the respective data-points after an additional tempering for $50 \mathrm{hr}$ at $250^{\circ} \mathrm{C}$. Figure 2(b) shows the difference between the values of resistivity before and after the tempering at $250^{\circ} \mathrm{C}$. The resistivity difference, divided by $29.5 \mu \Omega \cdot \mathrm{cm} / \mathrm{wt} \%$, gives the nominal dissolved carbon content.

The resistivity changes observed in the initial period of 4 sec include those attributable to the decrease of 

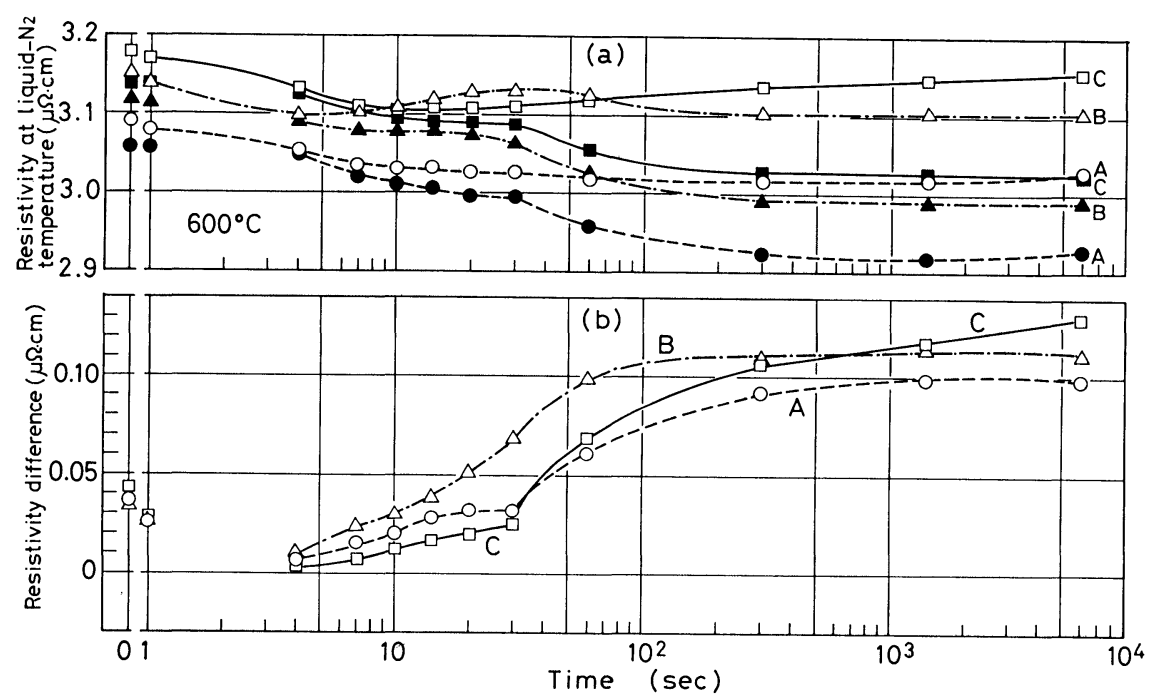

Fig. 2.

The data of electrical resistivity for the determination of nominal dissolved carbon content during isothermal annealing at $600^{\circ} \mathrm{C}$. Open marks plotted in Fig. 2 (a) are the data-points after annealing for various times at $600^{\circ} \mathrm{C}$, and filled marks in the same figure are those after additional tempering for $50 \mathrm{hr}$ at $250^{\circ} \mathrm{C}$. Figure 2 (b) shows the difference between the values before and after the tempering at $250^{\circ} \mathrm{C}$. Circle, triangle and square marks are for specimens A, B and C, respectively.
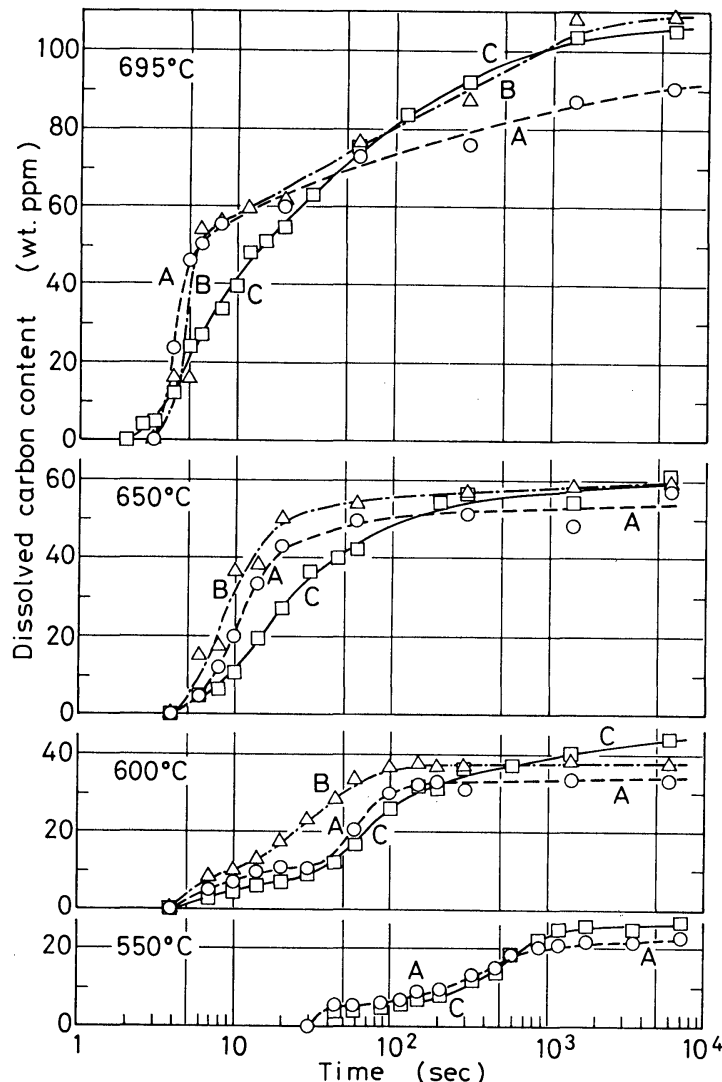

Fig. 3. Changes of nominal dissolved carbon content on annealing isothermally at $695^{\circ} \mathrm{C}, 650^{\circ} \mathrm{C}, 600^{\circ} \mathrm{C}$ and $550^{\circ} \mathrm{C}$.

dislocation density and the segregation of dissolved carbon atoms to dislocations ${ }^{5)}$ and are excluded from the scope of the present study.

The nominal dissolved carbon content vs. log time curves are summarized in Fig. 3. The rate of cementite dissolution is lowest in specimen $\mathrm{C}$ at every annealing temperature. At $600^{\circ} \mathrm{G}$ and $550^{\circ} \mathrm{C}$, two stages of dissolution are evident in the cases of specimens $\mathrm{A}$ and $\mathrm{C}$.

The fraction recrystallized vs. log time curves are shown in Fig. 4. Recrystallization commences earlier in specimen $\mathrm{C}$ than in the other two specimens on
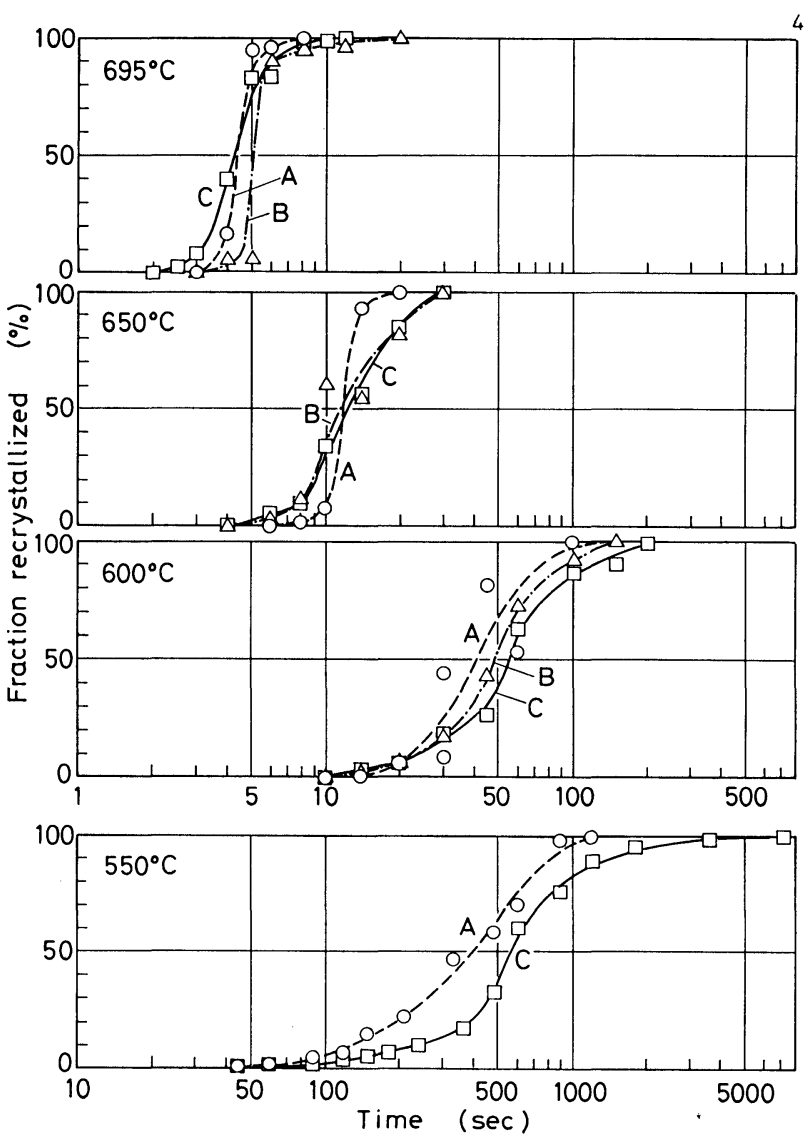

Fig. 4. Fraction recrystallized.

annealing at $695^{\circ} \mathrm{C}$, whereas specimen $\mathrm{A}$ recrystallizes faster than specimen $\mathrm{C}$ at $550^{\circ} \mathrm{C}$.

It should be noted that the microstructure of every specimen after recrystallization did not exhibit the "pancake" structure, but an equiaxed-grain structure. This suggests that the recrystallization process in every specimen had been little affected by the preprecipitation clusters of aluminium nitride.

Comparing Fig. 3 with Fig. 4 in the cases of annealing at $600^{\circ} \mathrm{C}$ and $550^{\circ} \mathrm{C}$, we see that the appearance of the above-mentioned two stages of cementite dissolution in specimens $\mathrm{A}$ and $\mathrm{C}$ can be related to 
the decrease in dislocation density during recrystallization. This suggests that the slow rate of dissolution during the first stage is not real but merely a result of the segregation of a part of the dissolved carbon to dislocations. Further it can be supposed that, regardless of the occurrence of such two stages of dissolution, the actual amounts of carbon dissolved at the isothermal annealing temperatures during the early stages must have been larger than those given in Fig. 3.

From the data given in Figs. 3 and 4, the fraction recrystallized is plotted against the dissolved carbon content in Fig. 5. In specimen A, the dissolved carbon content at a given level of fraction recrystallized decreases as the annealing temperature is lowered, whereas, in specimen $\mathrm{C}$, it is practically independent of the annealing temperature. At higher temperatures, specimen $\mathrm{G}$ recrystallizes in the deformed iron matrix with the lowest carbon content, but, at $550^{\circ} \mathrm{C}$, the dissolved carbon content in specimen $\mathrm{A}$ at $50 \%$ recrystallization is slightly lower than that in specimen C.

Figure 6 shows the changes in pole density for $\{222\},\{200\}$ and $\{110\}$ planes parallel to the sheet plane during isothermal annealing at $695^{\circ} \mathrm{C}, 650^{\circ} \mathrm{C}$, $600^{\circ} \mathrm{C}$ and $550^{\circ} \mathrm{C}$. The (200) pole density of every specimen after recrystallization lies at nearly random level independent of the annealing temperature. There is a general tendency of inverse correspondence between (222) and (110); an increase in (222) is always accompanied by a decrease in (110), and vice versa. The highest (222) is obtained in specimen $\mathrm{C}$ on annealing at $695^{\circ} \mathrm{C}$. In this case, the (222) pole density is increased, while the (110) pole density is decreased by partial grain growth during prolonged annealing. The lowest (110) pole density is obtained in specimen
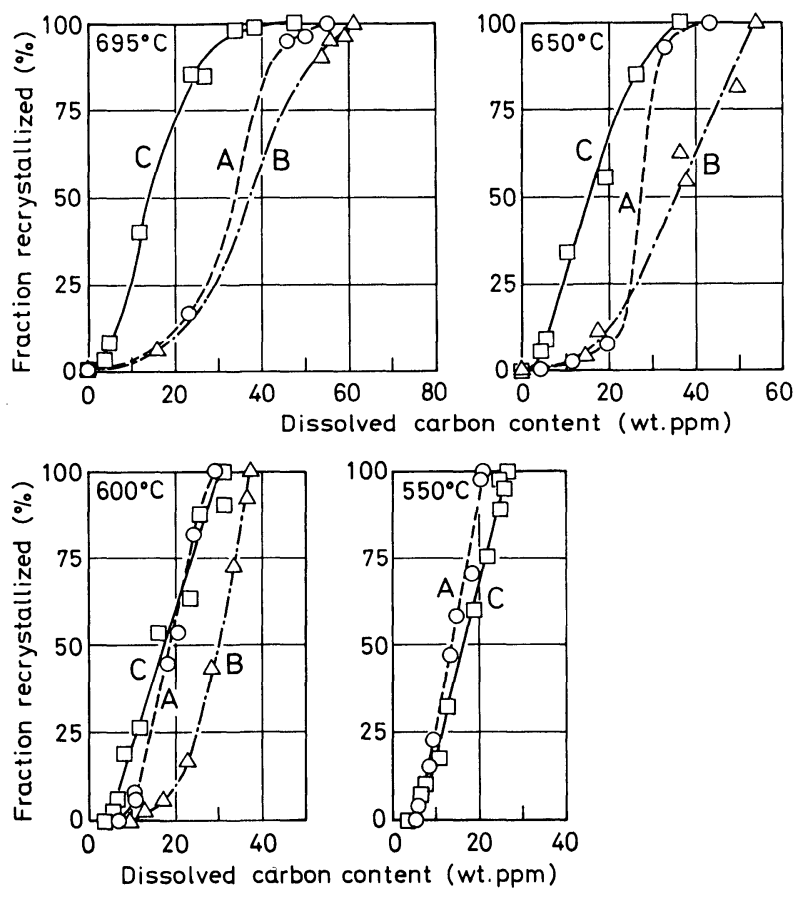

Fig. 5. Relation between fraction recrystallized and nominal dissolved carbon content.
A on annealing at $550^{\circ} \mathrm{C}$. For the primary recrystallization texture of this specimen, (110) is decreased, while (222) is increased by lowering the annealing temperature. After recrystallization at $550^{\circ} \mathrm{C}$, the (222) pole density of specimen $\mathrm{A}$ is higher than that of specimen C. The annealing texture of specimen $\mathrm{B}$ always exhibits low (222) and high (110).

A comparison of Fig. 6 with Fig. 5 leads to a provisional conclusion that, in agreement with the opinion proposed by Kubotera et al., ${ }^{2)}$ the recrystallization progressed in the iron matrix containing less amount of carbon in solution resulted in an annealing texture with stronger $\{222\}$ components.

The above result of the high-(222) and low-(110) annealing texture in specimen $\mathrm{A}$ on annealing at $550^{\circ} \mathrm{C}$ stimulated us to make an experiment of twostage annealing. After annealing for various times in a salt bath kept at $550^{\circ} \mathrm{C}$ followed by quenching, specimens $\mathrm{A}$ and $\mathrm{C}$ were additionally annealed in another salt bath kept at $700^{\circ} \mathrm{C}$ for $6000 \mathrm{sec}$. The data of (222) pole density after the two-stage annealing are shown in Fig. 7. Within the range of annealing conditions given in Fig. 7, the (222) pole density of specimen $\mathrm{A}$ is always higher than that of specimen C. The highest (222) pole density is obtained in specimen $\mathrm{A}$ by the first-stage annealing at $550^{\circ} \mathrm{C}$ for $300 \sim 400 \mathrm{sec}$ followed by the second-stage annealing at $700^{\circ} \mathrm{C}$ for a sufficient time.

Within the scope of the present study, it is concluded that specimen $\mathrm{G}$ is suitable to obtain a favourable annealing texture by rapid heating directly to a high temperature, but specimen $\mathrm{A}$ is more suitable to obtain a more favourable annealing texture through the two-stage annealing proposed here.

\section{Discussion}

Before entering into discussion, it should be pointed out that the experimental results obtained by annealing at higher temperatures cannot be regarded as those observed by "isothermal annealing" in a strict sense. Part of them should rather be regarded as those observed by "continuous heating". The dissolution of cementite into the iron matrix is so fast even at lower temperatures below $550^{\circ} \mathrm{G}$ that it proceeds to a certain extent before the whole test-piece is heated up to the temperature of the salt bath.

According to a preliminary test ${ }^{5)}$ of the heat transfer on immersing in the salt bath kept at $695^{\circ} \mathrm{C}$, the temperatures at the middle of the thickness of a testpiece after $1,2,3,4$ and 5 sec were $442^{\circ} \mathrm{C}, 619^{\circ} \mathrm{C}$, $683^{\circ} \mathrm{C}, 692^{\circ} \mathrm{C}$ and $693^{\circ} \mathrm{C}$, respectively. As shown in Fig. 3, the dissolution of cementite into the iron matrix on immersing in the salt bath kept at $695^{\circ} \mathrm{C}$ could be detected at 3 or $4 \mathrm{sec}$, and a considerable amount of carbon had been dissolved within a time of $5 \mathrm{sec}$. Thus, the dissolution of cementite in the early stages of annealing at $695^{\circ} \mathrm{C}$ cannot be treated as an isothermal process. The same may be said of the reactions on annealing at $650^{\circ} \mathrm{C}$ and $600^{\circ} \mathrm{C}$.

As seen in Fig. 4, recrystallization commenced also within a time of 3 or $4 \mathrm{sec}$ after immersing in the salt bath kept at $695^{\circ} \mathrm{C}$. Therefore, the data of frac- 


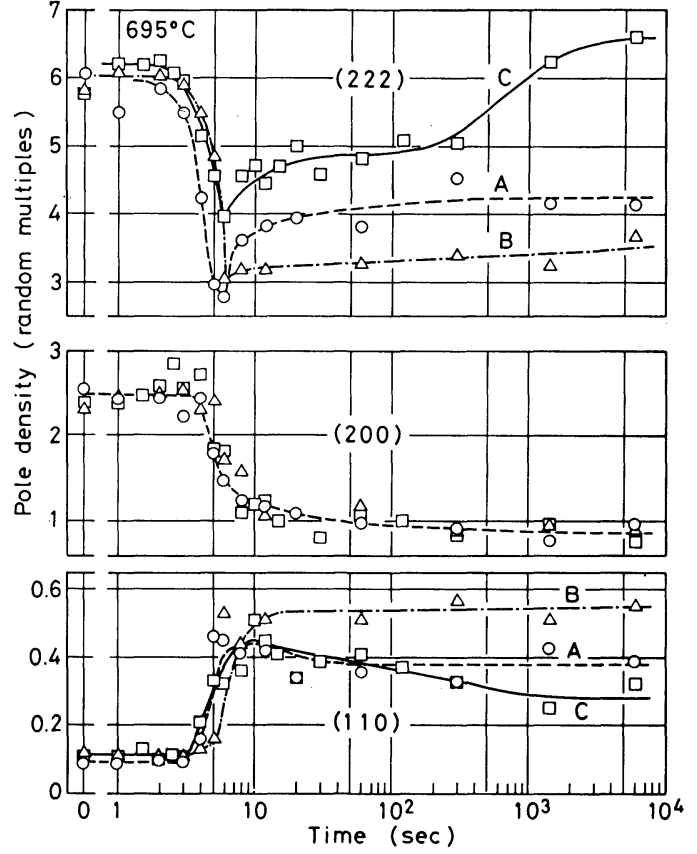

(a)

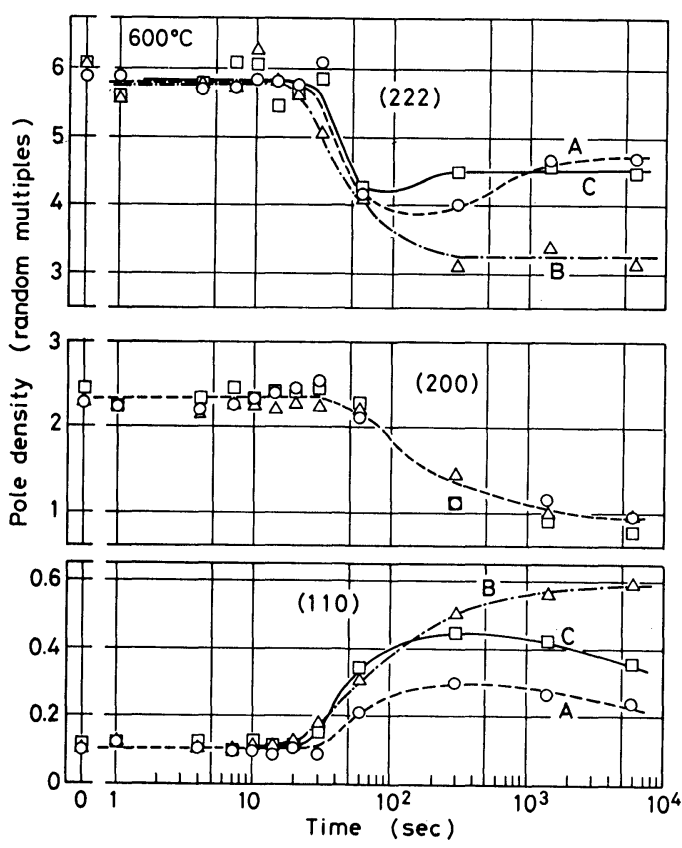

(c)

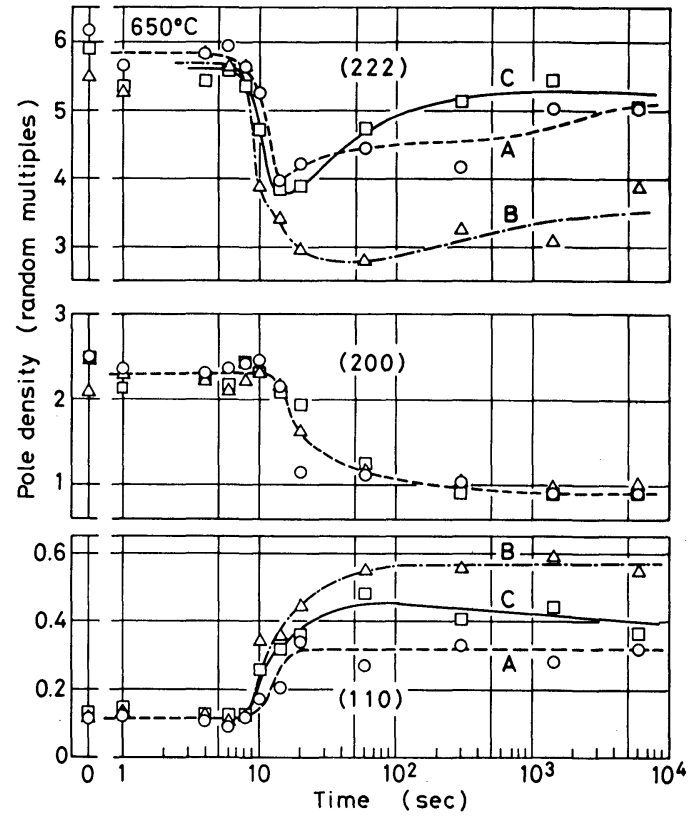

(b)
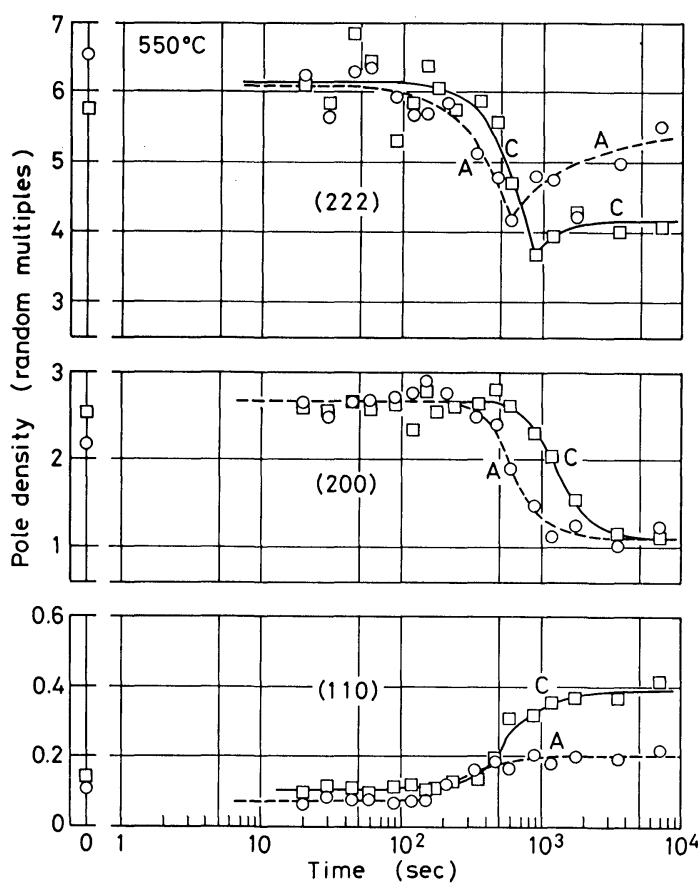

(d)

Fig. 6. Changes in pole densities of (222), (200) and (110) on annealing isothermally at (a) $695^{\circ} \mathrm{C}$, (b) $650^{\circ} \mathrm{C}$, (c) $600^{\circ} \mathrm{C}$ and (d) $550^{\circ} \mathrm{C}$.

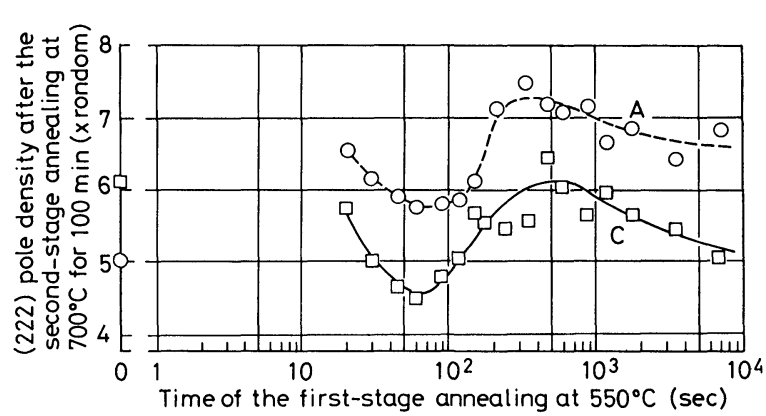

Fig. 7. Variations in (222) pole density for specimens A and $\mathrm{C}$ by two-stage annealing; the first-stage being at $550^{\circ} \mathrm{C}$ for various times, and the second-stage at $700^{\circ} \mathrm{C}$ for $100 \mathrm{~min}$. tion recrystallized also should not be treated as an isothermal process. Nevertheless, it can be noted that a plot of the times to $50 \%$ recrystallization against the reciprocal of absolute annealing temperature from the data given in Fig. 4 gives an activation energy of $55 \mathrm{kcal} \cdot \mathrm{mol},{ }^{-1}$ which is comparable to that of $60 \mathrm{kcal} \cdot \mathrm{mol}^{-1}$ for the self-diffusion in $\alpha$-iron.

From Figs. 5 and 6 , it was tentatively concluded that the recrystallization progressed in the deformed iron matrix containing less amount of carbon in solution led to the formation of an annealing texture with stronger $\{222\}$ sheet-plane orientations. Then, we must consider the role of the dissolved carbon atoms in the formation of the annealing texture. 
Recovery of the deformed matrix, or the nucleation of recrystallized grains, will be partially inhibited due to the pinning of dislocations by carbon atoms, since the binding energy of a carbon atom to dislocation is of the order of $\left.0.5 \mathrm{eV}^{8}\right)\left(0.8 \times 10^{-12} \mathrm{erg}\right)$ and is higher than the value of $k T, 1.3 \times 10^{-13} \mathrm{erg}$, at $695^{\circ} \mathrm{C}$. For the maximum dissolved carbon content at $695^{\circ} \mathrm{C}$, i.e. 110 wt.ppm (Fig. 3), the ratio $n_{d} / \mathcal{N}_{d}$ calculated from Eq. (1) is 0.066. When the dissolved carbon content is of the order of $1 \mathrm{wt}$.ppm, the ratio $n_{d} / \mathcal{N}_{d}$ is $6.5 \times 10^{-4}$. The carbon-concentration profiles around cementite particles during the early stages of annealing will make the nucleation in the vicinity of cementite particles more difficult than that in the regions far from the cementite-matrix interfaces.

On the other hand, as reported by Venturello et $a l .,{ }^{9,10)}$ the growth rate of recrystallized grains will be decreased slightly by carbon atoms. Venturello et al. considered the solute-drag motion of grain boundaries on the basis of the Lücke-Detert theory, ${ }^{11}$ ) but could not give a quantitative interpretation because of an extremely high mobility of carbon atoms at the recrystallization temperature. We have considered a slight decrease of the driving energy due to the segregation of solute atoms to dislocations. The driving energy for the growth of a recrystallized grain is the difference in strain energy between the interior of the recrystallized grain and the surrounding deformed matrix. The strain energy is held by dislocations. Therefore it must be lowered by the segregation of solute atoms to dislocations. ${ }^{12)}$ Assuming that the dislocation density of the deformed iron matrix is $\rho_{d} \mathrm{~cm} / \mathrm{cm}^{3}$, the binding energy of a carbon atom to dislocation about $0.5 \mathrm{eV}$, and the strain energy per unit length of dislocation $G b^{2}=$ $3.7 \times 10^{-4} \mathrm{erg} / \mathrm{cm}$, where $G$ is the shear modulus, and $b$ the Burgers vector, the segregation of $1 \mathrm{wt} . \mathrm{ppm}$ carbon to dislocations decreases the strain energy by $\left(0.86 \times 10^{11} / \rho_{d}\right) \%$. The maximum amount of carbon trapped by dislocations at $695^{\circ} \mathrm{C}$ is estimated to be $\left(0.67 \times 10^{-11} \cdot \rho_{d}\right)$ wt.ppm. Therefore, the decrease of the strain energy due to the segregation of carbon atoms to dislocations at $695^{\circ} \mathrm{C}$ would be less than $0.58 \%$ throughout the recrystallization process. Thus, the effect of dissolved carbon atoms on the driving energy is negligibly small in the present experiments.

From the above simple consideration, it is concluded that the recrystallization rate will be decreased by the dissolved carbon atoms through the inhibition of nucleation due to the pinning of dislocations, and a slight retard of the growth rate due to the solutedrag effect. According to this conclusion, recrystallization must proceed most rapidly in a specimen in which the cementite particles dissolve most slowly. This prediction, however, appears to be inconsistent with the results of Figs. 3 and 4.

For instance, on annealing at $695^{\circ} \mathrm{C}$, the recrystallization of a specimen $\mathrm{G}$ proceeded most quickly within a time of $3 \mathrm{sec}$, during which the dissolution of cementite could be detected solely in this specimen*. Recrystallization proceeded rapidly in specimen $\mathrm{B}$ on annealing at $650^{\circ} \mathrm{C}$, while the rate of cementite dissolution was most rapid in this specimen. The recrystallization of specimen $\mathrm{A}$ was evidently faster than that of specimen $\mathrm{C}$ on annealing at $550^{\circ} \mathrm{C}$, while the dissolved carbon content of specimen $\mathrm{A}$ was higher than that of specimen $\mathrm{G}$ within the time of $500 \mathrm{sec}$. These are marked examples showing that, contrary to the above prediction, recrystallization proceeded more quickly in the specimens with higher dissolved carbon contents. As mentioned earlier, however, the amounts of dissolved carbon atoms trapped by dislocations during quenching operation are not included in the nominal dissolved carbon contents given in Fig. 3. Since the nominal dissolved carbon content is the content of carbon atoms occupying the normal interstitial sites of the dislocation-free iron matrix, it increases with the decrease of dislocation density during recrystallization. Hence, the high value of the nominal dissolved carbon content can be regarded as a natural consequence of the rapid progress of recrystallization. We should be careful not to take the cause for the effect.

Inspection of the relation between the kinetics of recrystallization and the kinetics of cementite dissolution in every specimen at each temperature leads to a conclusion that there is no evidence that recrystallization proceeded more rapidly in a specimen with lower dissolved carbon content.

As discussed in a previous paper, ${ }^{5}$ the dissolution of cementite particles had already occurred to some extent before the thresholds of the curves given in Fig. 3. The carbon atoms dissolved before the threshold time had been trapped by dislocations and could not be evaluated in the present study.

A difficulty in the determination of the initial rate of cementite dissolution by measurements of bulk properties is how to analyse the concentration profiles. ${ }^{13,14)}$ Because of the presence of the carbonconcentration profile, the degree of the above-mentioned inhibiting effects may be a function of the distance from the cementite-matrix interface. This fact seems to be more important than the overall dissolution rate as a factor which controls the nucleation of recrystallized grains.

Now, we turn to another consideration on the effect of fine cementite particles on the growth of recrystallized grains. Following Zener's simple model, ${ }^{15)}$ it is expected that, for a given volume fraction of cementite, smaller particles hinder grainboundary migration more than large ones. Although direct observation has not been made on the change of cementite-particle size during isothermal annealing, it can be estimated from the mean size of cementite particles in the cold-rolled sheet by considering the fraction dissolved given from the data of Fig. 3. In the course of the argument, however, we were obliged to encounter a negative fact in the recrystallization

* The fast dissolution of cementite particles in specimen $\mathrm{C}$ despite of their large initial size may be partly attributed to the fragmentation of the cementite particles during cold rolling. 
kinetics shown in Fig. 4. That is, in the case of annealing at $550^{\circ} \mathrm{C}$, recrystallization proceeded faster in specimen A than in specimen G. Since the size of cementite particles was much smaller in specimen than in specimen $\mathrm{C}$, the faster recrystallization in specimen A seemed to contradict to the prediction from Zener's model.

Through the above discussion, we have not been able to give any consistent explanation of the results obtained in the present study. We now turn back to an old opinion, proposed by Abe and Takagi, ${ }^{16)}$ that the kinetics of recrystallization and the development of the recrystallization texture would be both controlled by the fine details of the deformed structure. The ideas originally proposed are inadequate and should be modified for the explanation of the present results.

The iron crystals surrounding cementite particles must undergo "constrained deformation". Changes in the size and spacing of cementite particles in a hot band will cause changes in the number, the distribution and the individual size of the "constraineddeformation regions" in the cold-rolled sheet. ${ }^{17)}$ These changes will affect the process of recrystallization. The following are the outlines of the results obtained by optical and electron microscopy.

In specimen $\mathrm{A}$, in which fine spheroidal cementite particles had been contained, a large number of small constrained-deformation regions were formed by cold rolling. On annealing the cold-rolled sheet, recrystallized grains first appeared in these constrained-deformation regions. ${ }^{18,19)}$ Because of the small size of these regions, at most two or three fine recrystallized grains per each were generated. Also in specimen $\mathrm{C}$, the recrystallized grains which appeared first on annealing at $695^{\circ} \mathrm{C}$ were found to nucleate around colonies of fragmented cementite particles (Photo. 2), but a large number of recrystallized grains per one colony could be observed. They were, in fact, responsible for the apparent earliest commencement of recrystallization in specimen $\mathrm{C}$ on annealing at $695^{\circ} \mathrm{C}$ (Fig. 4). Such a phenomenon has long been known and was clearly shown by Antonione et al. ${ }^{20)}$ for binary iron-carbon alloys. Despite the earliest commencement of recrystallization, the progress of recrystallization in specimen $\mathrm{G}$ was rather sluggish. This can be attributed partly to the smaller number of constrained-deformation regions, and partly to the lower dislocation density in the unconstraineddeformation regions far from the cementite-matrix interfaces. In this connection, it should be noted that the grain size of specimen $\mathrm{C}$ immediately after the end of primary recrystallization was larger than those of the other two specimens. As seen from Fig. 4, recrystallization on annealing at $600^{\circ} \mathrm{C}$ or $550^{\circ} \mathrm{C}$ commenced at nearly the same time in the three specimens. Then, recrystallization proceeded most rapidly in specimen A in which the number of constraineddeformation regions must have been largest.

Although the above explanation is incomplete, the kinetics of recrystallization shown in Fig. 4 would be satisfactorily explained if a more detailed metallogra-

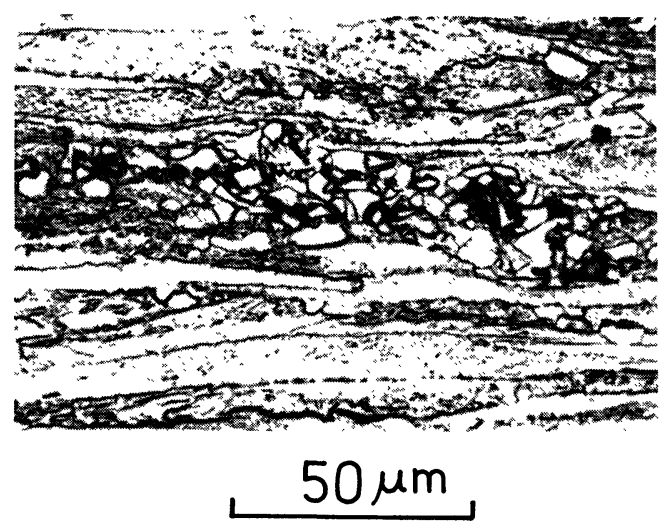

Photo. 2. Recrystallized grains first appeared around a colony of fragmented cementite particles in specimen $\mathrm{G}$ on annealing at $695^{\circ} \mathrm{C}$ for $3 \mathrm{sec}$.

phic observation could be made. Such an explanation is inevitably qualitative and affords little scope for quantitative interpretation. However, it is evident that the slight effect of the dissolved carbon was entirely covered by the large effect of constrained deformation around cementite particles. There appears to be little effect of the dissolved carbon on the kinetics of recrystallization in the steel used in the present study. The before-mentioned conclusion, that the recrystallization progressed in a deformed matrix containing less amount of carbon in solution resulted in an annealing texture with stronger $\{222\}$ components, seems to be merely a paraphrasing of the correspondence between the two phenomena both of which had been caused from the same origin, that is, the size and spacing of cementite particles contained in the hot band.

It is noteworthy that an annealing texture with the lowest $\{110\}$ components was obtained in specimen $\mathrm{A}$ on annealing at $550^{\circ} \mathrm{C}$. As seen in Fig. 6, the (110) pole density of specimen A after annealing decreased as the annealing temperature was lowered, that is, 0.38 at $695^{\circ} \mathrm{C}, 0.32$ at $650^{\circ} \mathrm{C}, 0.26$ at $600^{\circ} \mathrm{C}$, and 0.20 at $550^{\circ} \mathrm{C}$, whereas that of specimen $\mathrm{B}$ or $\mathrm{C}$ did not show such a remarkable temperature dependence. In the annealing texture of specimen $\mathrm{A}$, a decrease of the $\{110\}$ components was accompanied by an increase of the $\{222\}$ components, whilst the $\{200\}$ components were nearly kept constant; an annealing texture with lower $\{110\}$ along with higher $\{222\}$ components could be obtained by lowering the isothermal annealing temperature.

Such a remarkable temperature dependence of the annealing texture observed in specimen A cannot be interpreted as due to the effect of the dissolved carbon atoms, because specimen A shows no distinctive feature in the process of cementite dissolution compared with specimens B and G (Fig. 3).

The temperature dependence of the annealing texture in specimen A must have originated from its peculiar deformed structure characterized by densely distributed constrained-deformation regions. An explanation similar to but partly different from that given by Duggan and Roberts ${ }^{21)}$ may be applicable to 
the temperature dependence of the annealing texture. As shown by Smith and Dillamore, ${ }^{22)}$ the recrystallized grains with $\{222\}$ orientations must be generated by subgrain growth at lower temperatures. On the other hand, the annealing temperature should be high enough to allow high-angle boundary migration to occur for the growth of the nuclei with $\{110\}$ orientations. On the basis of these concepts, the temperature dependence of the annealing texture in specimen A may be explained, while the reason why the $\{110\}$ annealing-texture components in specimens $\mathrm{B}$ and $\mathrm{C}$ exhibit little dependence on temperature remains unexplained. It was imagined that, during the primary recrystallization, impingement between the $\{110\}$ grain and the $\{222\}$-grain must have frequently occurred in specimen A but scarcely occurred in specimen B or C. However, it is a tedious task to explore such an event.

According to Matsuo et al., ${ }^{23)}$ recrystallized grains generated in close vicinity to a large cementite particle exhibit a wide range of orientation-distribution including $\{110\}$ orientations, whilst those grown in regions far from cementite particles have a sharper orientation-distribution centred around $\{222\}$ sheet plane orientations. ${ }^{18,23)}$ On the other hand, Kishida and Takemoto ${ }^{24)}$ showed that both $\{110\}-$ and $\{222\}$ grains were equally generated in a region at a distance of more than $40 \mu \mathrm{m}$ from a large cementite particle, while $\{110\}$-grain was absent in the vicinity of the cementite-matrix interface. As mentioned before, the concentration profile in the early stages of cementite dissolution will function as a factor which controls the oriented nucleation. The higher carbon concentration in the vicinity of cementite-matrix interfaces might act to suppress the nucleation in the constrained-deformation regions. The temperature dependence of the annealing texture may probably be more or less influenced by the carbon-concentration profile. However, the two different reports ${ }^{23,24)}$ on the orientation-distribution lead to different interpretations on the effect of the carbon-concentration profile.

The idea of two-stage annealing proposed in the present study is essentially different from that of the conventional processing for aluminium-killed steels. ${ }^{25,26)}$ That tried here is based on the fact that the growth of $\{110\}$ components was suppressed while that of $\{222\}$ components was induced in specimen A by recrystallization at a lower temperature, whereas that of the conventional processing is to obtain the most favourable size and distribution of aluminiumnitride clusters by prior annealing. Comparing the (222) pole-density curve of Fig. 7 for specimen A with that of Fig. 6(d), we notice that the maximum (222) pole density attained after the second-stage annealing corresponds to a descending portion of the curve in Fig. 6(d). The first-stage annealing in a time period between 300 and $500 \mathrm{sec}$ gives the maximum (222) pole density after the second-stage annealing. According to Fig. 4, the fraction recrystallized at $550^{\circ} \mathrm{C}$ within the above time-period was at most $50 \%$. It is evident that the primary recrystal- lization had completed by the second-stage annealing. A striking fact is the parallelism between the two curves in Fig. 7. This suggests that the mechanism involved in the annealing-texture formation must be the same for these two specimens.

The conclusions of the present study are different from those by Takahashi and Okamoto ${ }^{27,28)}$ who showed that the annealing texture was greatly influenced by dissolved nitrogen. Since the solubility of nitrogen in ferrite is much higher than that of carbon and, in addition, the binding energy of a nitrogen atom to a dislocation may be larger than that of a carbon atom, the inhibition of the nucleation of recrystallized grains is presumed to be stronger in the case of nitrogen. This may be a reason of the difference in the ability of texture control between these two kinds of interstitial solute elements.

Throughout the present investigation, it has been assumed that the effects of various substitutional impurity atoms and of the precipitates of AIN and (Mn, Fe)S are nearly the same in the three specimens. These effects should be taken into consideration for the future studies of this series.

\section{Summary}

In processing from the hot band in which the cementite particles had been coarsened, an annealing texture with strong $\{222\}$ and weak $\{110\}$ components was obtained through rapid heating directly to $695^{\circ} \mathrm{C}$. In a case when the hot band contained fine spheroidal cementite particles, stronger $\{222\}$ and weaker $\{110\}$ components were attained through two-stage annealing; the first-stage being at $550^{\circ} \mathrm{C}$ for 3 or $5 \mathrm{~min}$, and the second-stage at $700^{\circ} \mathrm{C}$ for a sufficient time.

Inhibition of nucleation due to pinning of dislocations by dissolved carbon atoms and inhibition of the growth of recrystallized grains by carbon atoms or by fine cementite particles have been considered as probable effects which decrease the rate of recrystallization. The predictions were, however, found to be inconsistent with the experimental results obtained.

The observed differences in the processes of cementite dissolution, recrystallization and annealing-texture formation were all thought to originate from the differences in the size and spacing of cementite particles contained in the hot band. It was supposed that the size and spacing of cementite particles affected the formation of the annealing texture through changes in the size and distribution of constrained-deformation regions in the deformed iron matrix.

\section{Acknowledgements}

The authors wish to thank Mr. J. J. Lavigne for useful discussion.

\section{REFERENCES}

1) I. Gokyu, H. Abe and N. Ueyama: J. Japan Inst. Metals, 28 (1964), 542.

2) H. Kubotera, K. Nakaoka, K. Araki, K. Watanabe and K. Iwase: Tetsu-to-Hagané, 62 (1976), 846. 
3) The Recrystallization Committee of the Joint Society on Iron and Steel Basic Research: Recrystallization and Textures in Cold Rolled Sheets of Iron and Steels, ISIJ, (1974).

4) H. Abe, S. Nagashima, S. Hayami and K. Nakaoka: Proc. 5th. Intern. Conf. Textures of Materials, II, ed. by G. Gottstein and K. Lücke, Springer-Verlag, Berlin, (1978), 21.

5) H. Abe and T. Suzuki: Trans. ISIJ, 19 (1979), 689.

6) G. R. Speich: Trans. Met. Soc. AIME, 245 (1969), 2553.

7) W. Köster, L. Bangert and R. Hahn: Arch. Eisenhüttenw., 25 (1954), 569.

8) K. Kamber, D. Keefer and C. Wert: Acta Met., 9 (1961), 403.

9) G. Venturello, C. Antonione and F. Bonaccorso: Trans. Met. Soc. AIME, 227 (1963), 1433.

10) G. Antonione, G. Della Gatta and G. Venturello: Trans. Met. Soc. AIME, 230 (1964), 700.

11) K. Lücke and K. Detert: Acta Met., 5 (1957), 628.

12) A. H. Cottrell: Dislocations and Plastic Flow in Crystals, Oxford Univ. Press, London, (1953).

13) M.J. Whelan: Met. Sci. J., 3 (1969), 95.

14) H. B. Aaron and G. R. Kotler: Met. Sci. J., 4 (1970), 222.

15) G. Zener: Private communication to C. S. Smith: Trans. AIME, 175 (1949), 15.

16) H. Abe and K. Takagi: Tetsu-to-Hagané, 57 (1971), 1125.
17) U. Köster: Metal Science, 8 (1974), 151.

18) D. T. Gawne and G. T. Higgins: Texturen in Forschung und Praxis, ed. by J. Grewen and G. Wassermann, Springer-Verlag, Berlin, (1969), 319.

19) W. G. Leslie, J. T. Michalak and F. W. Aul: Iron and Its Dilute Solid Solutions, ed. by C. W. Spencer and F. E. Werner, Interscience Publishers, New York, (1963), 119.

20) G. Antonione, G. Della Gatta, A. Lucci and G. Venturello: Mém. Sci. Rev. de Métall., 65 (Numéro Spécial), (1968), 315 and 327.

21) B. J. Duggan and W. T. Roberts: Metal Science, 9 (1975), 449.

22) C.J.E. Smith and I. L. Dillamore: Met. Sci. J., 4 (1970), 161.

23) M. Matsuo, H. Hayakawa and S. Hayami: Tetsu-to-Hagané, 62 (1976), S 698.

24) K. Kishida and N. Takemoto: Tetsu-to-Hagané, 63 (1977), S 864.

25) H. Abe and T. Suzuki: Tetsu-to-Hagané, 56 (1970), 869.

26) Y. Meyzaud, B. Michaut and P. Parnière: Texture and the Properties of Materials, Proc. 4th Intern. Conf. Texture, The Metals Society, London, (1975), 255.

27) M. Takahashi and A. Okamoto: Tetsu-to-Hagané, 64 (1978), 2158.

28) M. Takahashi and A. Okamoto: Trans. ISIJ, 19 (1979), 391. 